\title{
Do home-visit programs for mothers with infants reduce parenting stress and increase social capital in Japan?
}

\section{Citation}

Fujiwara, Takeo, Keiko Natsume, Makiko Okuyama, Takuyo Sato, and Ichiro Kawachi. 2012. "Do Home-Visit Programs for Mothers with Infants Reduce Parenting Stress and Increase Social Capital in Japan?" Journal of Epidemiology and Community Health 66 (12): 1167-76. https:// doi.org/10.1136/jech-2011-200793.

\section{Permanent link}

http://nrs.harvard.edu/urn-3:HUL.InstRepos:41275599

\section{Terms of Use}

This article was downloaded from Harvard University's DASH repository, WARNING: This file should NOT have been available for downloading from Harvard University's DASH repository.

\section{Share Your Story}

The Harvard community has made this article openly available.

Please share how this access benefits you. Submit a story.

Accessibility 


\title{
Do home-visit programs for mothers with infants reduce parenting stress and increase social capital in Japan?
}

\author{
Takeo Fujiwara, ${ }^{1,2}$ Keiko Natsume, ${ }^{2,3}$ Makiko Okuyama, ${ }^{4}$ Takuyo Sato, \\ Ichiro Kawachi ${ }^{6}$
}

${ }^{1}$ Department of Social Medicine, National Research Institute for Child Health and Development Tokyo, Japan

${ }^{2}$ Department of Health Promotion, National Institute of Public Health, Saitama, Japan ${ }^{3}$ Department of Health and Welfare, Aichi Prefectural government, Aichi, Japan ${ }^{4}$ Department of Psychosocial Medicine, National Center for Child Health and Development Tokyo, Japan

${ }^{5}$ Department of Planning and Intelligence, Osaka Medical Center and Research Institute for Maternal and Child Health, Osaka, Japan

${ }^{6}$ Department of Society, Human Development, and Health, Harvard School of Public Health, Massachusetts, USA

\section{Correspondence to} Dr Takeo Fujiwara, Department of Social Medicine, National Research Institute for Child Health and Development, 2-10-1 Okura, Setagaya-ku, Tokyo 157-8535, Japan: tfujiwara@nch.go.jp

Accepted 4 March 2012

\section{ABSTRACT}

Background Distress during child rearing is known as a risk factor for child maltreatment. In addition, it is known that social capital can be a preventive factor for child maltreatment. The purpose of this study is to evaluate whether the home-visit program reduces parenting stress and increases the social capital in the community.

Methods The home-visit program was implemented when the infants were 1-2 month of age (by public health nurses or midwives) and/or 4 months of age for those mothers who agreed to a home visit by trained community staff. Self-administered questionnaires on parenting stress scale and social capital were sent to all mothers who delivered a baby between August and November 2009 in two cities in the Aichi prefecture, Japan.

Results Among 936 mothers, 347 mothers (follow-up rate: $37 \%$ ) completed both questionnaires. Scores on parenting stress scale scores at 4 months were lower than those at 1-2 months among the four groups (no home visit, home visit at 1-2 months, home visit at 4 months and both). The social trust scores at 4 months were higher than those at 1-2 months in every group; however, multivariate regression analysis showed that there were no differences in the reduction of the parenting stress scale scores and increase in social trust between the four groups.

Conclusion The home-visit program conducted once or twice by public health nurses or trained community staff for mothers with infants showed no substantial reduction in maternal stress and no increase in social trust.

\section{INTRODUCTION}

Addressing child maltreatment is a high-priority public health issue in Japan. Following the enactment of the Child Abuse Protection Law in Japan, the number of cases reported to the Child Guidance Center (which is analogous to the Child Protection Service in the UK or US) increased dramatically to a total of 40639 cases in 2007. This number has increased by around 40-fold since 1990 (1101 cases) and by 1.7-fold since 2001 (23274 cases). ${ }^{1}$ One study reported that $65 \%$ of the mothers in Japan do not have confidence in their parenting abilities, 33\% find parenting difficult and $18 \%$ believe that they maltreat their children. ${ }^{2}$ This suggests that a substantial proportion of mothers in Japan experience parenting distress, which is a significant risk factor for child maltreatment. ${ }^{3} 4$

A home-visit program can be an effective intervention to address parental needs. According to a review of 21 studies, home-visit programs for parents at risk of maltreating their children resulted in a $40 \%$ reduction in child maltreatment outcomes among the program participants compared with those who did not participate in a home-visit programme. ${ }^{5}$ This intervention was considered effective since it provided parents with information on child health and development and enabled them to develop problem-solving skills. ${ }^{6}$

In Japan, a home-visit program, 'Home Visit Service for Newborns', has existed since 1961 for 'mothers in need' with newborns, based on the Maternal and Child Health Act; visits are conducted by a public health nurse or midwife following discharge from the maternity ward. In this home-visit program, the nurse or midwife instructs mothers in need (eg, mothers with premature infants) on how to take care of the infants. Some municipalities have expanded this program to all mothers who expressed interest in the service when infants were 1-2 months of age.

It has been argued that child death cases attributable to maltreatment could occur in low-risk families, and most child deaths occur before the age of 4 months. Thus, as a parenting strategy and under the Child Welfare Law, the Ministry of Health, Labour and Welfare initiated the Home Visit Project for All Infants (Konnichiwa Akachan Jigyo) in 2007 in which trained community staff visit all families with infants younger than 4 months of age to focus on parenting stress and share information to aid parenting. This home-visit program was designed to be the point of first contact between mothers and their infants with the community. By fostering social connections, the home-visit program could be considered to be a 'social capital' intervention because the program provides mothers with greater access to social services and other resources in the community. ${ }^{6}$

Social capital is defined as the resources that individuals can access through their social connections to others. The resources available through social networks can take several distinct forms, including a) levels of trust between individuals, b) reciprocity exchanges and c) ability to undertake coordinated collective action. For example, a community with high social capital is one in which members frequently exchange favours for one another. These reciprocity exchanges in turn hinge on high levels of interpersonal trust (ie, trust that a recipient of a good deed will return the favour in the future). Therefore, a mother who received 
Figure 1 Flow chart of sample selection and allocation to four homevisit groups.

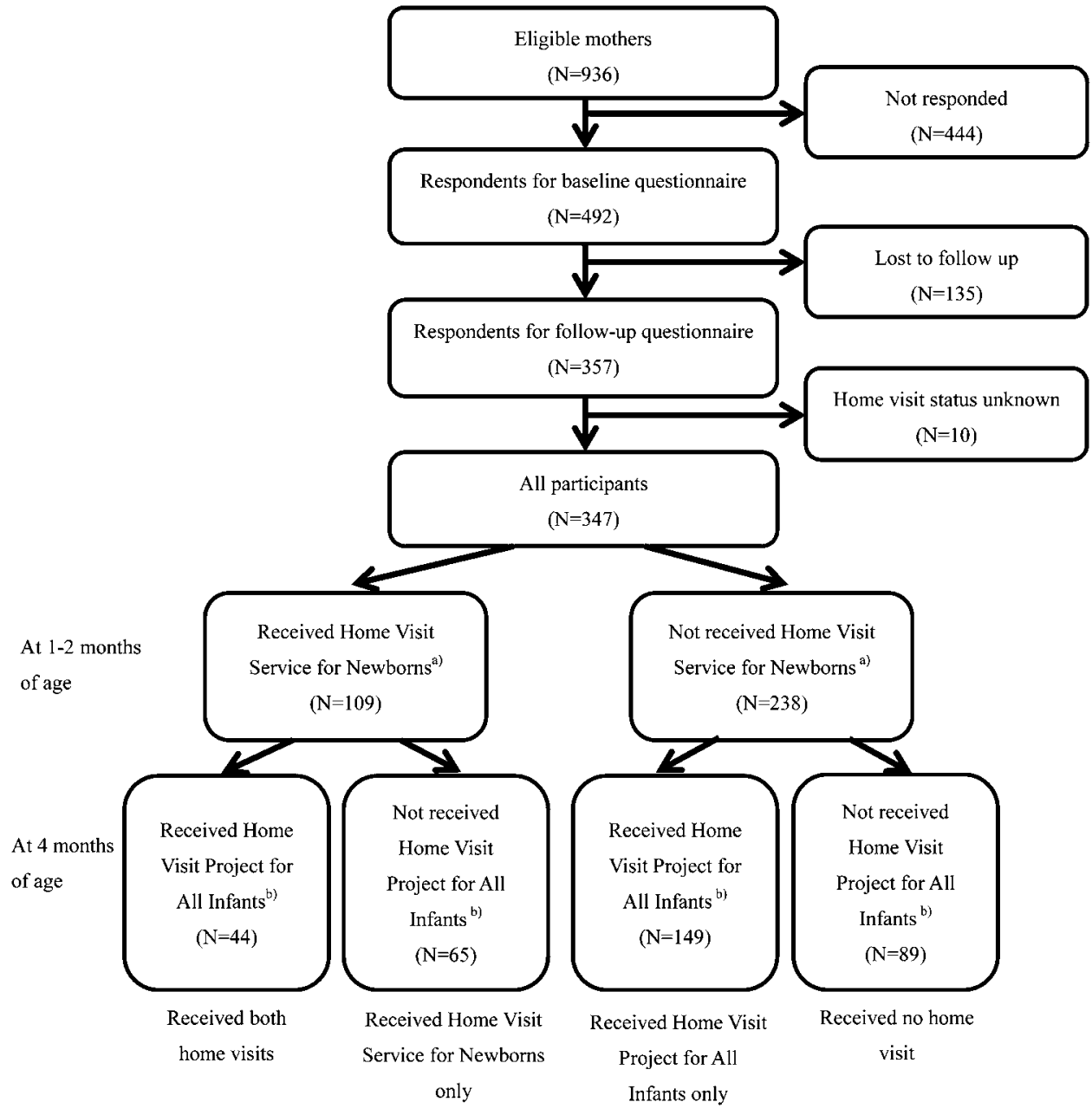

a) Home Visit Service for Newborns target mothers in need of help at 1-2 month of age, visited by public health nurse or midwife.

b) Home Visit Project for All Infants target for all infants until 4 month of age, visited by trained community staff, but some mothers can not receive the project due to absent from home. a home-visit program might enhance her cognitive social capital, such as social trust.

Thus, the purpose of this study is to evaluate whether the home-visit program implemented by public health nurses or midwives at $1-2$ months of age (Home Visit Service for Newborn) and home-visit program implemented by trained community staff until 4 months of age (Home Visit Project for All Infants) reduces parenting stress and increases perceptions of social capital in the community.

\section{METHODS}

\section{Sample}

The target subjects were all mothers $(\mathrm{N}=936)$ who had delivered a baby between August and November 2009 in Komaki and Inazawa Cities in Aichi prefecture, located in central Japan. Komaki City is located in a suburban area, north of Nagoya City, with a population of around 153000 with around 1400 births per year. Inazawa City is located in a suburban area, north-west of Nagoya City, with a population of around 138000 and around 1200 births per year. A baseline questionnaire was mailed directly to the target mothers, not distributed at the home visit, when the infants were 2-4 weeks of age, and a follow-up questionnaire was administered during a health check-up at
4 months of age. In total, baseline questionnaires were mailed to 932 mothers (four were returned with addressee unknown), of whom 492 responded (response rate: 53\%). Among these, 357 mothers responded to the follow-up questionnaire (response rate among baseline respondents: 73\%). Our study was approved by the Ethics Committee at National Institute for Public Health which determined that response to the questionnaire implied consent to participate in the study.

\section{Home-visit programs}

In both cities, there were two home-visit programs for newborn infants. The first program was Home Visit Service for Newborns, when infants were 1-2 months of age, wherein visits were conducted by a public health nurse or midwife for mothers with preterm infants with low birth weight and mothers who expressed interest in the service. Home Visit Service for Newborn is widely known among pregnant women, and those who expressed interest in the service are supposed to apply to their local public health centre. Approximately $19 \%$ and $13 \%$ of the newborns were visited in this home-visit service in Komaki and Inazawa Cities, respectively. The second program was part of Home Visit Project for All Infants, which arranges visits before the infants are 4 months of age. In both cities, all 
Table 1 Characteristics of sample $(\mathrm{N}=347)$

\begin{tabular}{|c|c|c|c|c|c|c|c|c|c|}
\hline & \multicolumn{2}{|c|}{$\begin{array}{l}\text { Received no } \\
\text { home visit } \\
\text { (N=89, 26\%) }\end{array}$} & \multicolumn{2}{|c|}{$\begin{array}{l}\text { Received home-visit } \\
\text { service for } \\
\text { newborn* only } \\
(\mathrm{N}=65,19 \%)\end{array}$} & \multicolumn{2}{|c|}{$\begin{array}{l}\text { Received home-visit } \\
\text { project for all } \\
\text { infants } \dagger \text { only } \\
(\mathrm{N}=149,43 \%)\end{array}$} & \multicolumn{2}{|c|}{$\begin{array}{l}\text { Received both } \\
\text { home-visit } \\
\text { projects } \ddagger \\
(\mathrm{N}=44,13 \%)\end{array}$} & p Value \\
\hline \multicolumn{10}{|l|}{ Maternal characteristics } \\
\hline \multicolumn{10}{|l|}{ Mother's age (years) } \\
\hline$<24$ & 7 & 7.9 & 6 & 9.2 & 7 & 4.7 & 3 & 6.8 & 0.016 \\
\hline $35+$ & 16 & 18.0 & 6 & 9.2 & 32 & 21.5 & 10 & 22.7 & \\
\hline Missing & 1 & 1.1 & 2 & 3.1 & 0 & 0.0 & 0 & 0.0 & \\
\hline \multicolumn{10}{|c|}{ Working status before or during pregnancy } \\
\hline House wife & 37 & 41.6 & 26 & 40.0 & 58 & 38.9 & 13 & 29.6 & 0.73 \\
\hline Part-time working & 16 & 18.0 & 13 & 20.0 & 30 & 20.1 & 13 & 29.6 & \\
\hline Full-time working & 35 & 39.3 & 22 & 33.9 & 61 & 40.9 & 18 & 40.9 & \\
\hline \multicolumn{10}{|l|}{ Child's characteristics } \\
\hline \multicolumn{10}{|l|}{ Sex } \\
\hline Girl & 49 & 55.1 & 25 & 38.5 & 64 & 43.0 & 19 & 43.2 & 0.17 \\
\hline Boy & 40 & 44.9 & 40 & 61.5 & 85 & 57.0 & 25 & 56.8 & \\
\hline \multicolumn{10}{|c|}{ Infant's age at first survey (week) } \\
\hline$<4$ & 12 & 13.5 & 8 & 12.3 & 28 & 18.8 & 9 & 20.5 & 0.27 \\
\hline 4 to $<8$ & 53 & 59.6 & 44 & 67.7 & 100 & 67.1 & 27 & 61.4 & \\
\hline $8+$ & 24 & 27.0 & 13 & 20.0 & 21 & 14.1 & 8 & 18.2 & \\
\hline \multicolumn{10}{|c|}{ Infant's age at second survey (week) } \\
\hline$<16$ & 26 & 29.2 & 15 & 23.1 & 29 & 19.5 & 6 & 13.6 & 0.12 \\
\hline 16 to $<20$ & 56 & 62.9 & 44 & 67.7 & 96 & 64.4 & 32 & 72.7 & \\
\hline $20+$ & 5 & 5.6 & 6 & 9.2 & 24 & 16.1 & 6 & 13.6 & \\
\hline \multicolumn{10}{|l|}{ Low birth weight } \\
\hline \multicolumn{10}{|l|}{ Family characteristics } \\
\hline Number of children & & & & & & & & & \\
\hline 1 & 43 & 48.3 & 37 & 56.9 & 55 & 36.9 & 27 & 61.4 & 0.031 \\
\hline 2 & 33 & 37.1 & 21 & 32.3 & 69 & 46.3 & 13 & 29.6 & \\
\hline $3+$ & 12 & 13.5 & 5 & 7.7 & 25 & 16.8 & 4 & 9.1 & \\
\hline Missing & 1 & 1.1 & 2 & 3.1 & 0 & 0.0 & 0 & 0.0 & \\
\hline Type of house & & & & & & & & & \\
\hline Detached house & 37 & 41.6 & 26 & 40 & 86 & 57.7 & 18 & 40.9 & 0.026 \\
\hline $\begin{array}{l}\text { Apartment/ } \\
\text { condominium building }\end{array}$ & 51 & 57.3 & 37 & 56.9 & 62 & 41.6 & 26 & 59.1 & \\
\hline Missing & 1 & 1.1 & 2 & 3.1 & 1 & 0.7 & 0 & 0.0 & \\
\hline Location & & & & & & & & & \\
\hline I city & 56 & 62.9 & 51 & 78.5 & 63 & 42.3 & 11 & 25.0 & $<0.001$ \\
\hline K city & 33 & 37.1 & 14 & 21.5 & 86 & 57.7 & 33 & 75.0 & \\
\hline Length of living in the & (year & & & & & & & & \\
\hline$<10$ & 63 & 70.8 & 46 & 70.8 & 97 & 65.1 & 32 & 72.3 & 0.75 \\
\hline 10 to $<20$ & 6 & 6.7 & 2 & 3.1 & 10 & 6.7 & 3 & 6.8 & \\
\hline $20+$ & 18 & 20.2 & 15 & 23.1 & 42 & 28.2 & 9 & 20.5 & \\
\hline Missing & 2 & 2.3 & 2 & 3.1 & 0 & 0.0 & 0 & 0.0 & \\
\hline Living with grandmother, & er or & & & & & & & & \\
\hline Yes & 15 & 16.9 & 11 & 16.9 & 30 & 20.1 & 10 & 22.7 & 0.81 \\
\hline No & 74 & 83.1 & 54 & 83.1 & 119 & 79.9 & 34 & 77.3 & \\
\hline
\end{tabular}


Table 1 Continued

\begin{tabular}{|c|c|c|c|c|c|c|c|c|c|}
\hline & \multicolumn{2}{|c|}{$\begin{array}{l}\text { Received no } \\
\text { home visit } \\
(\mathrm{N}=89,26 \%)\end{array}$} & \multicolumn{2}{|c|}{$\begin{array}{l}\text { Received home-visit } \\
\text { service for } \\
\text { newborn* only } \\
(\mathrm{N}=65,19 \%)\end{array}$} & \multicolumn{2}{|c|}{$\begin{array}{l}\text { Received home-visit } \\
\text { project for all } \\
\text { infants } \dagger \text { only } \\
(\mathrm{N}=149,43 \%)\end{array}$} & \multicolumn{2}{|c|}{$\begin{array}{l}\text { Received both } \\
\text { home-visit } \\
\text { projects } \ddagger \\
(\mathrm{N}=44,13 \%)\end{array}$} & \multirow[b]{2}{*}{ p Value } \\
\hline & $\mathbf{N}$ & $\%$ & $\mathbf{N}$ & $\%$ & $\mathbf{N}$ & $\%$ & N & $\%$ & \\
\hline \multicolumn{10}{|c|}{ Subjective economic status } \\
\hline Stable & 18 & 20.2 & 14 & 21.5 & 49 & 32.9 & 14 & 31.8 & 0.17 \\
\hline Fairly stable & 51 & 57.3 & 36 & 55.4 & 67 & 45 & 20 & 45.5 & \\
\hline Barely maintaining & 15 & 16.9 & 6 & 9.2 & 22 & 14.8 & 9 & 20.5 & \\
\hline Struggling & 4 & 4.5 & 7 & 10.8 & 11 & 7.4 & 1 & 2.3 & \\
\hline Missing & 1 & 1.1 & 2 & 3.1 & 0 & 0.0 & 0 & 0.0 & \\
\hline
\end{tabular}

Values in bold are significant (p) at the 0.05 level.

*Home-visit service for newborns targets mothers in need of help at 1-2 months of age, visited by public health nurses or midwives

tHome-visit project for all infants targets all infants until 4 month of age, visited by trained community staff.

¥Mothers who received both home-visit service for newborns and home-visit project for all infants.

the infants were supposed to be visited by trained community staff when they were around 4 months of age. However, some infants were not visited, mainly due to absence from home (eg, cases in which the infant was delivered and raised in the grandmother's hometown for the first several months, so the grandmother could help the mother out), and also partially due to inability to communicate because of a language barrier (ie, the mother was a non-Japanese speaker).

The contents of Home Visit Service for Newborns include (1) a health check-up for the newborn (measuring weight and head circumference; checking for feeding, stool or urination problems) and the mother (measuring blood pressure, checking lochia and breast excretion status) and (2) consultation on parenting in general. Home Visit Service for Newborns does not include intervention elements intended to directly to reduce maternal stress, but through teaching infant care skills, we may expect that maternal stress will be reduced. Further, the home visit assists mothers with infants to establish connections with their local public health centre, which may in turn boost social capital. Home Visit Project for All Infants includes (1) listening to maternal anxiety or distress about parenting, (2) information sharing on parenting support system, (3) check-up on maternal and child health status and home environment and (4) making connections with relevant sectors for families in need. In short, the home-visit project sought to increase social capital by establishing connections between local lay volunteers and mothers with infants. Maternal stress care was not part of the visit; however, the home visitor was instructed to look for signs of maternal distress. Thus, both home-visit programs could be considered to incorporate elements that helped to relieve maternal stress and build social capital.

The visitors are different across the two home visits. Visitors in Home Visit Service for Newborns are public health nurses or midwives, who graduated from a 4-year professional school for nurses, public health nurses and midwives and passed each national exam. On the other hand, visitors to Home Visit Project for All Infants are trained community staff selected from among those who already work as health promotion workers (hoken-renraku-in, in Komaki) and child welfare promotion workers (jido-iin, in Inazawa), as well as those who were taking care of children as volunteers. Furthermore, the trained community staff received around $8 \mathrm{~h}$ of specific training to prepare for the visit. The trained community staff was unpaid for this work. Approximately $89 \%$ and $84 \%$ of the infants were, respectively, visited as part of Home Visit Project for All Infants in Komaki and Inazawa Cities. Inazawa city did not implement a home-visit program by trained community staff if the mother participated in Home Visit Service for Newborns.

\section{Measurement of parenting stress and social capital}

Parenting stress was assessed using the parenting stress scale. ${ }^{7}$ This scale aims to measure parenting stress when infants are 6 months of age and was developed on the basis of the process model, ${ }^{8}$ in which child behaviours perceived as problematic were considered as child-related stress and maternal adaptability to respond to the problems was considered as mother-related stress. Child-related stress and mother-related stress comprised of 12 and 10 items assessed using a four-point Likert scale, and Cronbach's $\alpha$ coefficient was 0.86 and 0.90 , respectively.

Social capital was measured in two dimensions: social trust and sense of security in the community. Social trust and sense of security were each assessed by a single question, with responses on a four-point Likert scale. Similar questions were used in previous studies. $^{9} 10$

In addition, emotional support from other than family member was also assessed using the perceived emotional support scale, which has good internal reliability (Cronbach's $\alpha$ coefficient: 0.92) and good validity (Pearson's correlation coefficient: 0.34), according to the General Health Questionnaire. ${ }^{11}$ In this scale, the question 'Do you have anyone around you other than family?' was asked for 10 items (eg, a person who you feel comfortable with and relax when you meet with, a person who appreciates you, a person who you can disclose your feelings to, etc) with a yes or no response, and if the sum of the responses ('Yes' = 1 and 'No' = 0) was eight or more, the respondents were considered to have at least one person who appreciated and loved her, according to her perception. ${ }^{11}$

\section{Covariates}

The following possible covariates were obtained from the baseline questionnaire: mother's age, working status before or during pregnancy, current working status, child's gender, child's age at baseline and follow-up survey, preterm birth, low birth weight, number of children in the family, type of house, duration of stay in the city, living with relatives (eg, grandmother or grandfather) and subjective economic status. Subjective economic status was assessed using a four-point Likert scale as follows: stable, fairly stable, barely managing and struggling, developed on the basis of a previous study. ${ }^{12}$

\section{Analysis}

Among the 357 respondents to the follow-up questionnaire, 10 did not respond to the question on home-visit program 
Table 2 Association between sample characteristics and parenting stress scale and social capital at baseline

\begin{tabular}{|c|c|c|c|c|c|c|c|c|c|}
\hline & \multicolumn{3}{|c|}{ Parenting stress scale (total) } & \multicolumn{3}{|c|}{ Child-related stress scale } & \multicolumn{3}{|c|}{ Mother-related stress scale } \\
\hline & Mean (SD) & $\mathbf{F}$ & p Value & Mean (SD) & $\mathbf{F}$ & p Value & Mean (SD) & $\mathbf{F}$ & p Value \\
\hline \multicolumn{10}{|l|}{ Maternal characteristics } \\
\hline$<24$ & $34.2(7.4)$ & 0.40 & 0.75 & $20.2(4.5)$ & 0.58 & 0.63 & $14.0(3.7)$ & 2.18 & 0.090 \\
\hline $25-29$ & $35.5(8.2)$ & & & $20.4(5.3)$ & & & $15.1(4.2)$ & & \\
\hline $30-34$ & $36.2(8.9)$ & & & $20.3(5.5)$ & & & $15.9(4.3)$ & & \\
\hline House wife & $34.7(9.0)$ & 1.67 & 0.19 & $19.2(5.3)$ & 3.18 & 0.043 & $15.5(4.5)$ & 0.48 & 0.62 \\
\hline Part-time working & $36.6(8.6)$ & & & $20.5(5.5)$ & & & $16.1(4.3)$ & & \\
\hline Full-time working & $36.4(8.4)$ & & & $20.8(5.2)$ & & & $15.6(4.2)$ & & \\
\hline \multicolumn{10}{|l|}{ Current working status } \\
\hline Working & $33.2(7.6)$ & 0.75 & 0.39 & $18.4(3.3)$ & 0.92 & 0.34 & $14.8(4.7)$ & 0.29 & 0.59 \\
\hline Not working & $35.9(8.7)$ & & & $20.2(5.5)$ & & & $15.6(4.3)$ & & \\
\hline \multicolumn{10}{|c|}{ Infant's age at first survey (week) } \\
\hline$<4$ & $34.6(8.9)$ & 0.66 & 0.52 & $19.8(5.4)$ & 0.24 & 0.79 & $14.9(4.5)$ & 1.26 & 0.29 \\
\hline 4 to $<8$ & $36.0(8.7)$ & & & $20.3(5.4)$ & & & $15.7(4.3)$ & & \\
\hline $8+$ & $36.3(8.7)$ & & & $20.2(5.4)$ & & & $16.1(4.3)$ & & \\
\hline \multicolumn{10}{|c|}{ Infant's age at second survey (week) } \\
\hline$<16$ & $35.9(9.0)$ & 0.01 & 0.99 & $20.4(5.7)$ & 0.07 & 0.93 & $15.6(4.4)$ & 0.03 & 0.97 \\
\hline 16 to $<20$ & $35.8(8.8)$ & & & $20.2(5.5)$ & & & $15.6(4.4)$ & & \\
\hline $20+$ & $35.7(8.2)$ & & & $20.0(4.6)$ & & & $15.8(4.2)$ & & \\
\hline \multicolumn{10}{|l|}{ Preterm birth } \\
\hline$<37$ & $43.3(15.3)$ & 6.96 & 0.009 & $24.2(8.6)$ & 5.01 & 0.026 & $19.2(7.0)$ & 6.25 & 0.013 \\
\hline $37+$ & $35.6(8.4)$ & & & $20.1(5.3)$ & & & $15.5(4.2)$ & & \\
\hline \multicolumn{10}{|l|}{ Low birth weight } \\
\hline \multicolumn{10}{|l|}{ Family characteristics } \\
\hline Detached house & $34.3(8.6)$ & 8.53 & 0.004 & $18.9(5.3)$ & 16.4 & $<0.001$ & $15.4(4.4)$ & 0.76 & 0.38 \\
\hline $\begin{array}{l}\text { Apartment/ } \\
\text { condominium building }\end{array}$ & $37.0(8.5)$ & & & $21.1(5.2)$ & & & $15.8(4.3)$ & & \\
\hline Location & & & & & & & & & \\
\hline I city & $36.3(9.1)$ & 1.19 & 0.28 & $20.3(5.6)$ & 0.09 & 0.77 & $16.0(4.4)$ & 3.34 & 0.069 \\
\hline $\mathrm{K}$ city & $35.3(8.3)$ & & & $20.1(5.2)$ & & & $15.2(4.2)$ & & \\
\hline Length of living in the ch & city (year) & & & & & & & & \\
\hline$<10$ & $35.9(8.5)$ & 0.48 & 0.62 & $20.2(5.2)$ & 0.41 & 0.67 & $15.7(4.3)$ & 0.48 & 0.62 \\
\hline 10 to $<20$ & $33.9(9.0)$ & & & $19.2(5.6)$ & & & $14.8(4.0)$ & & \\
\hline $20+$ & $35.8(9.1)$ & & & $20.3(5.9)$ & & & $15.5(4.6)$ & & \\
\hline Living with grandmother, & ffather or relat & & & & & & & & \\
\hline Yes & $34.6(8.8)$ & 1.69 & 0.19 & $19.1(5.3)$ & 3.31 & 0.070 & $15.5(4.5)$ & 0.12 & 0.73 \\
\hline No & $36.1(8.7)$ & & & $20.4(5.4)$ & & & $15.7(4.3)$ & & \\
\hline Subjective economic sta & & & & & & & & & \\
\hline Stable & $33.7(8.0)$ & 3.09 & 0.027 & $18.9(5.2)$ & 2.87 & 0.036 & $14.8(4.0)$ & 2.11 & 0.099 \\
\hline Fairly stable & $36.9(8.9)$ & & & $20.8(5.4)$ & & & $16.1(4.5)$ & & \\
\hline Barely maintaining & $35.2(8.8)$ & & & $20.0(5.4)$ & & & $15.1(4.3)$ & & \\
\hline Struggling & $37.0(8.2)$ & & & $21.0(5.4)$ & & & $16.0(4.3)$ & & \\
\hline Social trust & & & & & & & & & \\
\hline Not at all & $39.5(8.6)$ & 7.46 & $<0.001$ & $22.0(5.4)$ & 5.55 & 0.001 & $17.1(4.6)$ & 6.33 & $<0.001$ \\
\hline Rarely & $37.4(8.6)$ & & & $21.1(5.5)$ & & & $16.4(4.4)$ & & \\
\hline Some & $34.5(8.5)$ & & & $19.5(5.3)$ & & & $15.0(4.1)$ & & \\
\hline Very & $31.9(7.4)$ & & & $18.1(4.6)$ & & & $13.8(3.7)$ & & \\
\hline
\end{tabular}


Table 2 Continued

\begin{tabular}{|c|c|c|c|c|c|c|c|c|c|}
\hline & \multicolumn{3}{|c|}{ Parenting stress scale (total) } & \multicolumn{3}{|c|}{ Child-related stress scale } & \multicolumn{3}{|c|}{ Mother-related stress scale } \\
\hline & Mean (SD) & $\mathbf{F}$ & p Value & Mean (SD) & $\mathbf{F}$ & p Value & Mean (SD) & $\mathbf{F}$ & p Value \\
\hline \multicolumn{10}{|c|}{ Sense of security } \\
\hline Not at all & $38.4(10.5)$ & 6.36 & $<0.001$ & $20.2(5.9)$ & 5.09 & 0.002 & $18.2(5.3)$ & 5.67 & $<0.001$ \\
\hline Rarely & $38.3(8.6)$ & & & $21.7(5.4)$ & & & $16.7(4.4)$ & & \\
\hline Some & $36.0(8.6)$ & & & $20.3(5.4)$ & & & $15.7(4.3)$ & & \\
\hline Very & $32.0(7.7)$ & & & $18.1(4.9)$ & & & $14.0(3.7)$ & & \\
\hline \multicolumn{10}{|c|}{ Perceived emotional support scale from others } \\
\hline$<7$ & $37.6(9.2)$ & 7.02 & 0.008 & $21.1(5.7)$ & 4.44 & 0.036 & $16.5(4.7)$ & 7.26 & 0.007 \\
\hline $8+$ & $34.9(8.4)$ & & & $19.7(5.3)$ & & & $15.2(4.1)$ & & \\
\hline
\end{tabular}

Values in bold are significant at the $p=0.05$ level.

status, resulting in a final sample size of $n=347$ (follow-up rate among target population, $37 \%$ ). The participants were divided into four groups on the basis of home-visit status, as follows: did not receive a home visit $(n=89,26 \%$ ), received one home visit conducted by a public health nurse or midwife when the infant was 1-2 months of age (ie, took part in Home Visit Service for Newborns only) ( $n=65,19 \%)$, received one home visit conducted by a trained community staff person when the infant was around 4 months of age (ie, took part in Home Visit Project for All Infants) $(n=149,43 \%)$ and received both home visits $(n=44,13 \%)$ (figure 1). First, demographic data and other characteristics were compared between the four groups using the $\chi^{2}$ test. Second, an association between the demographic data and other characteristics, social capital indicators and parenting stress was investigated using analysis of variance (ANOVA). Finally, the differences in parenting stress and social capital indicators at baseline and follow-up were assessed using the paired $t$ test, and differences among the four groups were assessed using multivariate regression analysis, after adjusting for potential covariates and baseline values.

\section{RESULTS}

Participants' characteristics are listed in table 1. A few differences were found. Mothers who received Home Visit Service for Newborns only were younger than mothers in the other groups $(p=0.016)$. Mothers who received Home Visit Project for All Infants only predominantly lived in detached houses $(p=0.026)$. Characteristics such as the duration of stay in the city, living with relatives (eg, grandmother, grandfather or others) and subjective economic status did not differ between the groups.

The association between maternal, child and family characteristics and the parenting stress scale scores is given in table 2 . Having a boy or a preterm infant or having larger number of children, living in an apartment or condominium building or lower subjective economic status were associated with higher parenting stress. Furthermore, social trust and sense of security showed a significant inverse association with parenting stress $(\mathrm{p}<0.001)$.

The association between maternal, child and family characteristics and social capital indicators is given in table 3 . Older women, being housewives before and during pregnancy, having larger number of children or living in detached houses showed higher social trust or sense of security. Further, mothers who were struggling showed less social trust and sense of security than those who felt stable ( $p<0.01$ for both).

The effects of the home-visit programs on parenting stress and social capital indicators are listed in table 4. ANOVA indicated significant differences between groups in the baseline and follow-up scores for parental distress. However, there was no statistically significant difference in the change in parental distress between different groups $(p=0.43)$. The multivariable regression analyses similarly did not indicate statistically significant differences between groups. Similarly, child-related parenting stress and maternal stress were significantly reduced in the follow-up survey; however, group differences were not observed.

Social trust was significantly increased only in the group that received Home Visit Service for Newborns only (2.58 vs 2.29, $95 \%$ CI 0.07 to 0.46 ). The increment was compared between the groups using ANOVA and multivariate analysis, and no difference was observed ( $p=0.14)$. Sense of security was significantly increased only in the group that received Home Visit Project for All Infants only. No significant differences between groups were observed using ANOVA and multivariate analysis $(p=0.35)$. The percentage of mothers with a high score on the perceived emotional support scale increased in every group; however, the increment was not significantly different between the groups.

\section{DISCUSSION}

This study revealed that, in Japan, compared with mothers who did not participate in home-visit programs, mothers who participated in home-visit programs conducted by public health nurses or midwives at 1-2 months after delivery and/or for all infants by trained community staff until 4 months after delivery did not show significant reduction in parenting stress. Similarly, social capital indicators were higher among women who participated in home-visit programs, but the increase over time was not significantly different compared with those who did not participate in home-visit programs. This finding suggests that current form of home-visit programs for mothers with infants in Japan failed to increase those mothers' social capital.

Previous studies have reported the impact of home-visit programs on the social support for mothers. Marcenko and Spence ${ }^{13}$ reported that home-visit programs for women at risk of out-of-home placement of their newborns resulted in increased social support and greater access to services. However, McCurdy ${ }^{14}$ reported that home-visit programs for disadvantaged mothers who gave birth in Hawaii did not foster social support when the infant became 12 months of age. Similarly, it was also reported that a home-visit intervention delivered by a paraprofessional for American Indian mothers did not result in a change in social support. ${ }^{15}$ Although social support and social capital are not the same, our findings add to the literature that home-visit programs for high-risk and low-risk mothers do not result in increase in social capital.

To the best of our knowledge, this study is the first attempt to evaluate the impact on social capital of home-visit programs for 
Table 3 Association between sample characteristics and social capital and emotional support at baseline

\begin{tabular}{|c|c|c|c|c|c|c|c|c|c|c|}
\hline & \multicolumn{3}{|l|}{ Social trust } & \multicolumn{3}{|c|}{ Sense of security } & \multicolumn{4}{|c|}{ Perceived emotional support scale } \\
\hline & Mean (SD) & $\mathbf{F}$ & p Value & Mean (SD) & $\mathbf{F}$ & p Value & $\leq 7, \mathbf{N}(\%)$ & $\geq 8, \mathbf{N}(\%)$ & $\chi^{2}$ & p Value \\
\hline \multicolumn{11}{|l|}{ Maternal characteristics } \\
\hline$<24$ & $2.25(0.79)$ & 2.64 & 0.049 & $2.89(0.61)$ & 0.88 & 0.45 & $7(7.3)$ & $17(6.9)$ & 1.77 & 0.62 \\
\hline $25-29$ & $2.39(0.93)$ & & & $2.93(0.68)$ & & & $26(27.1)$ & $76(30.7)$ & & \\
\hline $30-34$ & $2.60(0.78)$ & & & $3.00(0.69)$ & & & $41(42.7)$ & $113(45.6)$ & & \\
\hline House wife & $2.68(0.87)$ & 8.28 & $<0.001$ & $3.07(0.69)$ & 6.79 & 0.001 & $34(35.4)$ & $103(41.9)$ & 1.34 & 0.51 \\
\hline Part-time working & $2.64(0.66)$ & & & $3.01(0.62)$ & & & $20(20.8)$ & $50(20.3)$ & & \\
\hline Full-time working & $2.31(0.84)$ & & & $2.78(0.69)$ & & & $42(43.8)$ & $93(37.8)$ & & \\
\hline \multicolumn{11}{|l|}{ Current working status } \\
\hline Working & $2.88(0.83)$ & 1.46 & 0.23 & $3.25(0.46)$ & 1.61 & 0.21 & $3(3.1)$ & $5(2.0)$ & 0.37 & 0.54 \\
\hline Not working & $2.51(0.83)$ & & & $2.94(0.69)$ & & & $94(96.9)$ & $245(98.0)$ & & \\
\hline \multicolumn{11}{|c|}{ Infant's age at first survey (week) } \\
\hline$<4$ & $2.68(0.76)$ & 1.61 & 0.20 & $3.09(0.61)$ & 2.58 & 0.077 & $14(14.4)$ & $42(16.8)$ & 0.33 & 0.85 \\
\hline 4 to $<8$ & $2.51(0.87)$ & & & $2.95(0.69)$ & & & $64(66.0)$ & $158(63.2)$ & & \\
\hline $8+$ & $2.42(0.76)$ & & & $2.81(0.71)$ & & & $19(19.6)$ & $50(20.0)$ & & \\
\hline \multicolumn{11}{|c|}{ Infant's age at second survey (week) } \\
\hline$<16$ & $2.54(0.94)$ & 0.51 & 0.60 & $3.04(0.65)$ & 1.42 & 0.24 & $26(27.1)$ & $53(21.4)$ & 1.76 & 0.42 \\
\hline 16 to $<20$ & $2.50(0.78)$ & & & $2.90(0.68)$ & & & $61(63.5)$ & $163(65.7)$ & & \\
\hline $20+$ & $2.64(0.91)$ & & & $3.02(0.75)$ & & & $9(9.4)$ & $32(12.9)$ & & \\
\hline \multicolumn{11}{|l|}{ Preterm birth } \\
\hline$<37$ & $2.11(0.78)$ & 2.26 & 0.13 & $2.89(0.60)$ & 0.07 & 0.80 & $1(1.0)$ & $8(3.2)$ & 1.30 & 0.25 \\
\hline $37+$ & $2.53(0.83)$ & & & $2.95(0.69)$ & & & $96(99.0)$ & $242(96.8)$ & & \\
\hline \multicolumn{11}{|l|}{ Low birth weight } \\
\hline Detached house & $2.70(0.79)$ & 15.9 & $<0.001$ & $3.05(0.72)$ & 8.49 & 0.004 & $42(44.2)$ & $120(48.4)$ & 0.48 & 0.49 \\
\hline $\begin{array}{l}\text { Apartment/ } \\
\text { condominium building }\end{array}$ & $2.35(0.85)$ & & & $2.84(0.64)$ & & & $53(55.8)$ & $128(51.6)$ & & \\
\hline Location & & & & & & & & & & \\
\hline I city & $2.49(0.84)$ & 0.74 & 0.39 & $2.96(0.67)$ & 0.23 & 0.64 & $50(51.6)$ & $133(53.2)$ & 0.08 & 0.78 \\
\hline $\mathrm{K}$ city & $2.56(0.83)$ & & & $2.93(0.70)$ & & & $47(48.5)$ & $117(46.8)$ & & \\
\hline Length of living in the $\mathrm{cu}$ & city (year) & & & & & & & & & \\
\hline$<10$ & $2.45(0.83)$ & 1.52 & 0.22 & $2.95(0.68)$ & 0.18 & 0.84 & $70(72.9)$ & $166(67.2)$ & 3.52 & 0.17 \\
\hline 10 to $<20$ & $2.43(0.93)$ & & & $2.86(0.79)$ & & & $8(8.3)$ & $13(5.3)$ & & \\
\hline $20+$ & $2.65(0.83)$ & & & $2.94(0.68)$ & & & $18(18.8)$ & $68(27.5)$ & & \\
\hline Living with grandmother, & dfather or rela & & & & & & & & & \\
\hline Yes & $2.54(0.75)$ & 0.03 & 0.87 & $2.93(0.70)$ & 0.08 & 0.78 & $17(17.5)$ & $46(18.4)$ & 0.04 & 0.85 \\
\hline No & $2.52(0.85)$ & & & $2.95(0.68)$ & & & $80(82.5)$ & $204(81.6)$ & & \\
\hline Subjective economic stat & & & & & & & & & & \\
\hline Stable & $2.79(0.79)$ & 5.07 & 0.002 & $3.13(0.67)$ & 4.40 & 0.005 & $18(18.8)$ & 79 (31.9) & 6.22 & 0.10 \\
\hline Fairly stable & $2.44(0.82)$ & & & $2.91(0.64)$ & & & $54(56.3)$ & $117(47.2)$ & & \\
\hline Barely maintaining & $2.39(0.82)$ & & & $2.77(0.74)$ & & & $16(16.7)$ & $38(15.3)$ & & \\
\hline Struggling & $2.27(0.94)$ & & & $2.77(0.81)$ & & & $8(8.3)$ & $14(5.7)$ & & \\
\hline
\end{tabular}

Values in bold are significant at the $p=0.05$ level.

mothers with infants. The lack of an effect of the home-visit programs for mothers with infants needs careful interpretation. First, Home Visit Service for Newborns is not intended to increase social capital; rather, it is intended to support infant care among mothers who need help. Nonetheless, it is inter- esting that mothers who received Home Visit Service for Newborns showed significantly higher social trust at 4 months, while mothers who received Home Visit Project for All Infants did not show an increase. This is probably because mothers visited by a public health nurse or midwife in Home Visit Service 
Table 4 Effects of home visit on parenting stress, social capital and perceived emotional support from others

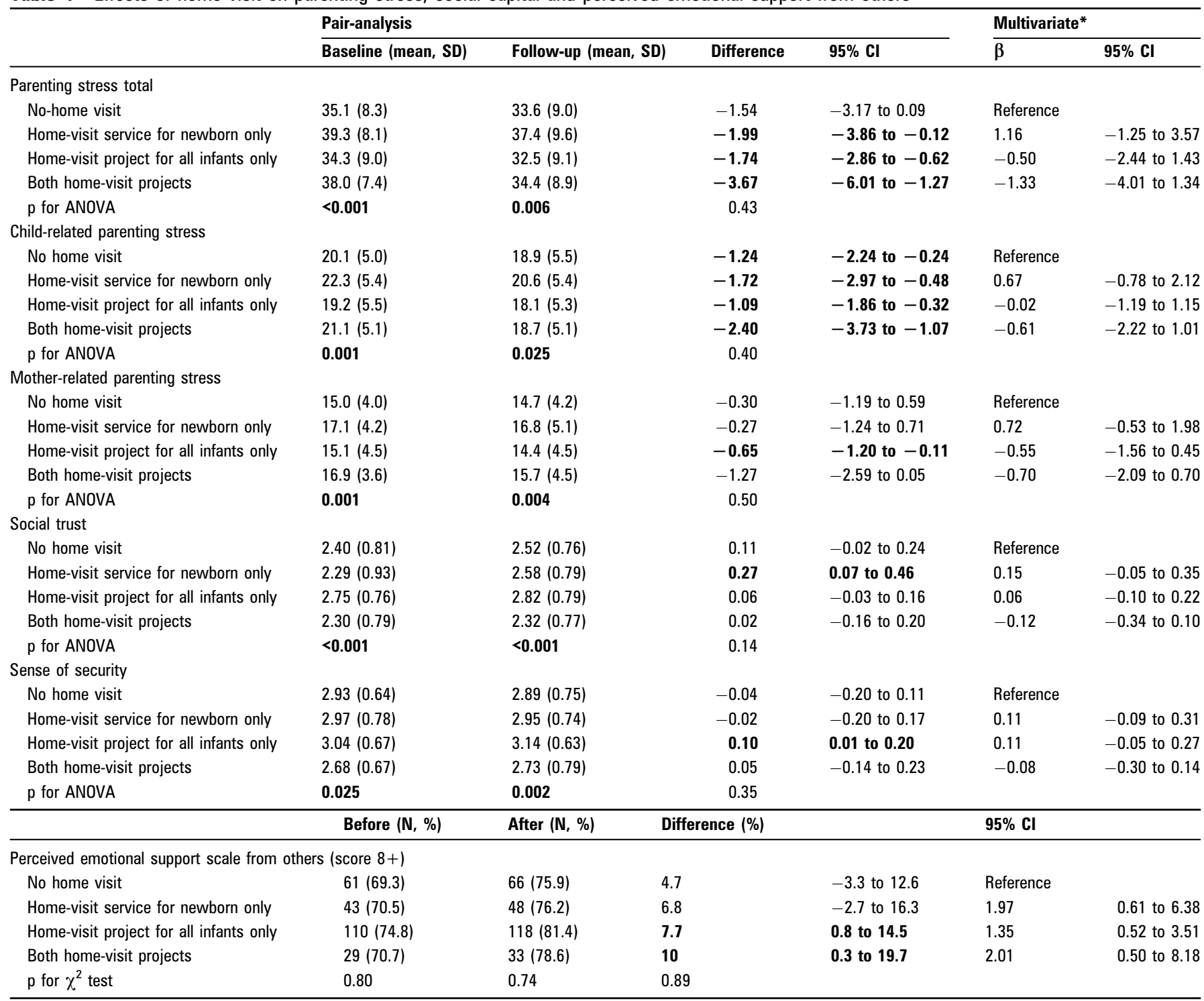

Values in bold are significant at the $p=0.05$ level.

*Adjusted for mother's age, working status when pregnant, child's sex, child's age (week), preterm, number of children at home, type of house, city, duration of years living in the current city, living with relatives, subjective socioeconomic status, parenting stress scale at 1 month, social trust at 1 month, sense of security at 1 month, perceived emotional support from others at 1 month (score $8+$ or not).ANOVA, analysis of variance.

for Newborns initially had lower social trust levels (at 1-2 months), while social trust among mothers visited by trained community staff in Home Visit Project for All Infants was higher. Regarding sense of community security, mothers who received visits under Home Visit Project for All Infants showed a significant increase in sense of security. Although sense of security tended to improve among mothers who participated in the home-visit program conducted by trained community staff, the estimates were not significantly higher than the group receiving no home visit, suggesting that the observed increase among mothers receiving home visits by trained community staff might be due to confounds.

The score on the perceived emotional support scale was higher at follow-up among mothers who received Home Visit Project for All Infants or both home-visit programs in comparison with the baseline (ie, pair-analysis), suggesting that trained community staff are viable candidates for providing emotional support, although comparison with the no-home-visit group was not significant in the multivariate model. It has been speculated that emotional support, rather than structural support, exerts a more powerful impact on parenting behaviour. ${ }^{16}$ Further randomised controlled trials are required to investigate whether home visits by professionals or trained community staff result in an increase in emotional support.

Participation in home-visit programs decreased parenting stress, but the reduction might be attributable to a time effect because the reduction is not significant in comparison with that in mothers who received no home visit. The low intensity of the home-visit program (at most, twice in the first 4 months) was likely insufficient to adequately deal with maternal stress. It has been reported that an intense home-visit program, such as the Nurse Family Partnership program (1 h 15 min home visits, 23 times on average until the child's second birthday), showed significant improvement (ie, reduction) in levels of dysfunctional caregiving concentrated among mothers with low levels of psychological resources. ${ }^{17}$ In contrast, other results from randomised controlled trials showed that home-visit programs did not reduce parenting stress. For example, it has been reported 
that parenting stress was not reduced among American Indian mothers who participated in a home-visit program (1-h home visits, 25 times) when the infant was $2-12$ months of age. ${ }^{15}$ Other statewide home-visit programs also showed no effect on maternal mental health. ${ }^{18}$ Nonetheless, provision of information on infant crying in the first few months of age, which is a partial cause of maternal stress, ${ }^{19}$ might reduce abusive head trauma in infants ${ }^{20}$ because an infant's cry is a major trigger of abusive head trauma. ${ }^{21} 22$ Recent randomised controlled trials revealed that providing educational material on infant crying led to significant changes in knowledge and behaviour and the reduction of abusive head trauma. ${ }^{23} 24$ Thus, home-visit programs for mothers with infants in the first few months should include education on how to deal with infant crying.

Our study had several limitations. First, the home-visit programs were not assigned randomly. Although we adjusted for known covariates, unmeasured confounding factors such as home environment ${ }^{25}$ or personality might have influenced the association. Further study is warranted, including randomised controlled trials, to investigate the effectiveness of home-visit programs on maternal stress and social capital. Second, the parenting stress scale is supposed to be used for infants who are 6 months of age; thus, the scale might not be appropriate to measure parenting stress in mothers with infants who are 1-4 months of age. However, the items used in this scale were considered to match with those of parents with infants who were 1-4 months of age. Further studies are required to validate the use of the parenting stress scale for parents with younger infants. Third, the duration of follow-up (2-3 months) might be too short to evaluate the change in the social capital. A longer duration of follow-up might show a different effect. Further study is warranted to investigate the effect of home-visit programs with a longer follow-up duration. Fourth, although this was a population-based survey, only $37 \%$ of the eligible population responded to the follow-up survey. Unfortunately, the participants were identified from the birth records, which included only the name and address of the newborn, and thus, a comparison of relevant characteristics between respondents and non-respondents at baseline is not possible. Thus, selection bias cannot be avoided, which limits the generalisability of the findings. Further, we only know whether the subjects received

\section{What is already known on this subject}

A home-visit program can be an effective intervention to address maternal parenting stress.

- No study investigated the effectiveness of home-visit program on maternal parenting stress and social capital simultaneously.

\section{What this study adds}

The home-visit program for mothers with infants once or twice showed no substantial reduction in maternal parenting stress and no substantial increase in social trust in Japan.

- Further research in the form of randomised controlled trials is required to confirm the effectiveness of intensive home-visit programs. the home-visit program from the follow-up questionnaire, and thus, we could not test whether 'exposure' to the home-visit program was associated with response to the follow-up questionnaire. However, the response rate was not likely to be differential with respect to what type of program they received because the comparison between respondents and non-respondents to the follow-up questionnaire showed no significant difference on covariates. In addition, we included only mothers who delivered infants between August and November 2009, but there might be a seasonal variation on the impact of home-visit programs.

Despite these limitations, we found that home-visit programs have potential to reduce parenting stress and increase the social capital. Although not statistically significant, we found an association between the frequency of home visits and reduction in parenting stress. The type of visitor (ie, public health nurses, midwives or trained community staff) needs to be chosen carefully. Further randomised controlled trials are required to determine the appropriate frequency of home visits and to identify the most suitable person to conduct home-visit programs.

In conclusion, home-visits programs implemented once or twice by public health nurses or trained community staff for mothers with infants were not associated with substantial reductions in maternal stress and increase in social trust. Further research in the form of randomised controlled trials is required to confirm the effectiveness of intensive home-visit programs.

Acknowledgements We appreciate all the participants who completed the questionnaires despite of busy child-rearing periods.

Contributors TF conceived research design, data analysis and wrote first draft. KN conceived research design and collected data. MO, TS and IK provided professional comments and edited the final manuscript.

Funding This study is partly supported by grant from Ministry of Health, Labour and Welfare (H23-Seisaku-Ippan-005).

\section{Competing interests None.}

Patient consent We used questionnaire and fill out of the questionnaire was considered consent, which was approved by Ethics Committee at National Institute of Public Health.

Ethics approval This study was approved by the Ethics Committee at the National Institute of Public Health.

Provenance and peer review Not commissioned; externally peer reviewed.

\section{REFERENCES}

1. Children's Rainbow Center. Child Abuse In Japan Today, And Measures For Its Prevention. Kanagawa: Children's Rainbow Center, 2009.

2. Nihon Shouni Hoken Kyokai (The Japanese Society of Child Health). Heisei 12 Nendo Youji Kenkoudo Chousa Houkokusyo (Report of Survey on Health Status of Toddlers, FY2000). Tokyo: Nihon Shouni Hoken Kyokai (The Japanese Society of Child Health), 2001.

3. Taylor CA, Guterman NB, Lee SJ, et al. Intimate partner violence, maternal stress, nativity, and risk for maternal maltreatment of young children. Am J Public Health 2009:99:175-83.

4. Cadzow SP, Armstrong KL, Fraser JA. Stressed parents with infants: reassessing physical abuse risk factors. Child Abuse Negl 1999;23:845-53.

5. Hahn RA, Bilukha 00, Crosby A, et al. First reports evaluating the effectiveness of strategies for preventing violence: early childhood home visitation. Findings from the task force on community preventive services. MMWR Recomm Rep 2003;52:1-9.

6. Yoshikawa $\mathbf{H}$. Long-term effects of early childhood programs on social outcomes and delinquency. Future Child 1995:5:51-75.

7. Sato T, Sugawara M, Toda M, et al. Association of parenting stress and severity of depression. Shinrigaku Kenkyu 1993:64:409-16.

8. Lazarus RS, Folkman S. Stress, Appraisal, and Coping. New York: Springer, 1984

9. Fujiwara T, Kawachi I. A prospective study of individual-level social capital and major depression in the United States. J Epidemiol Community Health 2008;62:627-33 
10. Fujiwara T, Kawachi I. Social capital and health a study of adult twins in the U.S. Am J Prev Med 2008;35:139-44.

11. Munakata T, Nakao T, Fujita K, et al. Stress and mental health among urban population. Seishin Eisei Kenkyu 1986;32:47-68.

12. Demakakos $\mathbf{P}$, Nazroo J, Breeze E, et al. Socioeconomic status and health: the role of subjective social status. Soc Sci Med 2008;67:330-40.

13. Marcenko MO, Spence M. Home visitation services for at-risk pregnant and postpartum women: a randomized trial. Am J Orthopsychiatry 1994;64:468-78.

14. McCurdy K. Can home visitation enhance maternal social support? Am J Community Psychol 2001;29:97-112.

15. Walkup JT, Barlow A, Mullany BC, et al. Randomized controlled trial of a paraprofessional-delivered in-home intervention for young reservation-based American Indian mothers. J Am Acad Child Adolesc Psychiatry 2009;48:591-601.

16. Thompson R. Social support and the prevention of child maltreatment. In: Melton G, Barry F, eds. Protecting Children from Abuse and Neglect. New York: The Guilford Press, 1994:40-130.

17. Olds DL, Henderson CR Jr, Kitzman HJ, et al. Prenatal and infancy home visitation by nurses: recent findings. Future Child 1999;9:44-65, 190-1.

18. Duggan A, Fuddy L, Burrell $L$, et al. Randomized trial of a statewide home visiting program to prevent child abuse: impact in reducing parental risk factors. Child Abuse Negl 2004;28:623-43.
19. Barr RG. The normal crying curve: what do we really know? Dev Med Child Neurol 1990;32:356-62

20. Dias MS, Smith K, DeGuehery K, et al. Preventing abusive head trauma among infants and young children: a hospital-based, parent education program. Pediatrics 2005; 115:e470-7.

21. Barr RG, Trent RB, Cross J. Age-related incidence curve of hospitalized shaken baby syndrome cases: convergent evidence for crying as a trigger to shaking. Child Abuse Neglect 2006;30:7-16.

22. Fujiwara T, Barber C, Schaechter J, et al. Characteristics of infant Homicides: findings from a U.S. Multisite reporting system. Pediatrics 2009;124: e210-17.

23. Barr RG, Barr M, Fujiwara T, et al. Do educational materials change knowledge and behaviour about crying and shaken baby syndrome? A randomized controlled trial. CMAJ 2009;180:727-33.

24. Barr RG, Rivara FP, Barr M, et al. Effectiveness of educational materials designed to change knowledge and behaviors regarding crying and shaken-baby syndrome in mothers of newborns: a randomized, controlled trial. Pediatrics 2009:123: 972-80.

25. Kendrick D, Elkan R, Hewitt M, et al. Does home visiting improve parenting and the quality of the home environment? A systematic review and meta analysis. Arch Dis Child 2000;82:443-51. 